\title{
UMA PROPOSTA DE DESIGN NA LEITURA: REFLEXÕES SOBRE SUJEITOS, OBJETOS- LIVRO E POLÍTICAS PÚBLICAS PARA A FORMAÇÃO DO LEITOR
}

\author{
Maíra Gonçalves Lacerda e Jackeline Lima Farbiarz
}

livros para crianças e jovens, políticas públicas de fomento à leitura, Design na Leitura.

\begin{abstract}
A partir da apresentação do conceito de Design na Leitura e da reflexão a respeito dos lugares ocupados pelo Design nos livros de literatura voltados para crianças e jovens chancelados pelas políticas públicas, o presente artigo procura avaliar as relações existentes entre sujeitos leitores, objetos-livro e políticas públicas para a formação do leitor. A exposição do processo metodológico desenvolvido para análise gráfica de livros selecionados pelo Programa Nacional Biblioteca da Escola (PNBE), para os jovens estudantes dos anos finais do Ensino Fundamental, e apresentação dos dados encontrados resultaram na elaboração de propostas que visam contribuir para a consolidação do Design como campo interdisciplinar junto às diretrizes nacionais de fomento à leitura.
\end{abstract}

This paper evaluates the relationships among readers, books and public policies for readers' education based on the presentation of the concept of Design in Reading and the reflection on the role of Design in literature books targeted at children and young people that are recognized by public policies. The methodology involved the graphic analysis of books that were selected by the National Program of School Libraries (Programa Nacional Biblioteca da Escola-PNBE) for young students at the last years of Basic Education. This analysis resulted in proposals that aim at contributing to the consolidation of Design as an interdisciplinary field in national guidelines for reading promotion.

\section{INTRODUÇÃO}

Segundo Bartolomeu Campos de Queirós, as palavras, como portas e janelas, descortinam horizontes, e o livro, enquanto suporte primordial para essas palavras, se constitui como objeto fundamental 
no trajeto de cada indivíduo em sua própria existência. Para o escritor, um dos criadores do Movimento por um Brasil Literário, é na ficção e na fantasia que o ser humano encontra liberdade para pensar sobre a sua realidade e configurar alternativas reais para a modificação social, o que torna um projeto literário também em uma ação política (Queirós, 2009). Dessa forma, o livro de literatura para crianças e jovens, isto é, o objeto destinado para o leitor em formação, carrega em si esse potencial transformador, peça importante na viabilização de um país mais digno por meio do desenvolvimento da subjetividade do indivíduo. Nesse processo, qual o papel do designer ao dar materialidade a um livro de literatura para crianças e jovens? Como o Design vem sendo abordado nas políticas públicas de incentivo à leitura para crianças e jovens?

Procurando ponderar sobre essas perguntas, o presente artigo tem por objetivo apresentar o conceito de Design na Leitura e refletir a respeito dos lugares ocupados pelo Design nos livros de literatura voltados para crianças e jovens chancelados pelas políticas públicas. Ao avaliarmos as relações existentes entre os sujeitos leitores, os objetos-livro e as políticas públicas de formação do leitor, por meio da análise gráfica de livros selecionados pelo Programa Nacional Biblioteca da Escola - PNBE, chegamos à elaboração de algumas propostas e recomendações que visam contribuir para a consolidação do Design como campo interdisciplinar junto às diretrizes nacionais de fomento à leitura.

\section{DESENVOLVIMENTO: apresentando conceitos, metodologia e alguns resultados}

O Design na Leitura é um conceito recente, que vem se definindo por meio de múltiplos trabalhos acadêmicos e oferece nova possibilidade metodológica para sustentação de análises no âmbito do Design da Informação. Enquanto o Design do livro se refere unicamente ao projeto do objeto-livro em si, o Design na Leitura, em ampliação à ideia anterior, é a concepção de um projeto para a mediação do ato de ler. Podendo ser definido como projeto interdisciplinar com vistas à fruição do futuro leitor, pensado como ser social e dinâmico, visando ao seu diálogo com o objeto-livro e todas as pessoas participantes de sua produção, o Design na Leitura originou-se na compreensão do livro enquanto objeto criado de forma coletiva e interdisciplinar por diversos profissionais de diferentes áreas, que alcança sua significação na relação com o sujeito leitor. Contudo, constantemente em um processo editorial convencional, os agentes produtores do objeto-livro não se comunicam. As tarefas se desenvolvem de forma separada e sequencial: o escritor escreve, o ilustrador ilustra, o designer une todo o material produzido ao dar forma ao objeto, e o editor publica. Esse trabalho realizado de forma fragmentada não aproveita o potencial de 
diálogo que permeia o objeto-livro, possibilitando que se estabeleça um processo comunicacional entre seus diversos criadores e seus variados leitores, isto é, não alcança o Design na Leitura.

A partir desse conceito, e procurando avaliar os lugares ocupados pelo Design nos livros de literatura voltados para jovens estudantes e chancelados pelas políticas públicas, estabeleceu-se uma metodologia construída nos âmbitos do levantamento, seleção, concepção e desenvolvimento de categorias para análise dos livros selecionados pelo Programa Nacional Biblioteca da Escola - PNBE. Esta análise envolveu a categorização de 50 livros selecionados pelo PNBE 2011 para atender os estudantes dos anos finais do Ensino Fundamental ( 6 ㅇ a $9^{\circ}$ ano), o que possibilitou o acesso a um conjunto de livros representativo do mercado editorial voltado para esse público. A categorização formulada, organizada em seis tipologias, teve por base o pensamento de Linden (2011), Haslam (2007) e Lupton \& Phillips (2008), permitindo olhar para os objetos-livro a partir de uma perspectiva do Design, por meio de conceitos e critérios pertencentes à própria área de conhecimento.

\subsection{Tipologia em relação ao espaço ocupado pela ilustração}

Para analisar o espaço ocupado pela ilustração nos livros para jovens estudantes foram organizadas as seguintes categorias: livros sem ilustração, livros com até $25 \%$ de páginas ilustradas, livros com 25 a 50\% de páginas ilustradas e livros com mais de 50\% de páginas ilustradas (incluindo histórias em quadrinhos). Por essa classificação, percebe-se que o acervo estudado possui na sua composição uma maioria de livros onde a imagem é espacialmente preponderante. Livros com mais de $25 \%$ de páginas ilustradas ocupam juntos $66 \%$ dos livros selecionados, sendo $36 \%$ referentes a livros com mais de $50 \%$ de páginas ilustradas, parecendo identificar a necessidade de objetoslivro que se utilizam da imagem para, juntamente com o texto, compor a narrativa para o jovem estudante. Esse dado surpreende, pois, de acordo com o senso comum instaurado, esperava-se encontrar uma representatividade maior de obras onde o texto ocupasse o espaço principal, encaminhando o jovem leitor para os livros considerados como leitura para adultos.

\subsection{Tipologia em relação à presença de diferencial gráfico}

Com a identificação da grande presença de imagens nos livros, buscou-se verificar se existia a ocorrência de elementos de Design que se destacassem nas obras analisadas. Para isso, foram organizadas novas categorias a partir da Paleta do designer de livros, de Haslam (2007), que explora as maneiras pelas quais o designer pode abordar um texto para dar forma a um livro, isto é, formato, malha gráfica, 
tipografia e tipo. Partindo dessa organização, foram estruturadas três categorias que visam identificar projetos que destaquem algum dos elementos acima citados (devido à proximidade dos conceitos, tipografia e tipo foram unidos em uma única categoria); além da cor, que foi adicionada como elemento devido a sua grande presença nos livros selecionados. A classificação dos livros nas categorias livro com trabalho diferenciado no formato, livro com trabalho diferenciado na malha gráfica, livro com trabalho tipográfico diferenciado e livro com trabalho cromático diferenciado, foi realizada de acordo com a percepção, muitas vezes subjetiva, da ênfase dada pelo projeto do livro ao componente do Design em questão, procurando identificar aqueles em que o elemento de Design sobressai na composição da página e participa do processo de produção de sentidos do texto. Tal classificação não foi realizada a partir de uma perspectiva de valor, positivo ou negativo, mas apenas de possibilitar um olhar a respeito da participação dos elementos descritos no design dos livros selecionados.

Por essa categorização, observa-se que 30 livros, ou seja $60 \%$ do acervo, não apresentam nenhum trabalho de Design que se destaque na apresentação de seus conteúdos. Apesar de a imagem ocupar espaço significativo nas obras formadoras do acervo do PNBE, e, em consequência, participar fortemente do processo de constituição do objeto-livro voltado para o jovem estudante na concepção do mercado editorial e dos especialistas do programa, o mesmo não acontece, aparentemente, com o Design. Dentre os elementos selecionados para essa categorização, a cor é a que apresenta maior representatividade, com 15 livros apresentando um trabalho cromático diferenciado, sendo que muitas vezes tal trabalho encontra-se atrelado às ilustrações e não ao design do livro propriamente dito.

\subsection{Tipologia em relação às instâncias de significação}

Procurando compreender melhor a relação entre texto e imagem nos livros para jovens, e aprofundar as informações a respeito dos dados encontrados até então, foram utilizadas algumas categorizações de Linden (2011) para analisar os livros do acervo que possuem ilustrações (44 livros). As funções do texto e da imagem são descritas pela autora em função da ideia de primazia e prioridade de uma das linguagens na veiculação da narrativa. Isso significa que, quando o texto é o principal veiculador da história, ele constitui a instância primária do livro, deixando a imagem como instância secundária; por outro lado, quando a imagem é mais relevante para a narrativa, ela se torna a instância primária e o texto exerce a função de instância secundária. Contudo, algumas vezes, a articulação das duas linguagens não permite que se defina uma primazia; consequentemente é a interação entre texto e imagem que ocupa o lugar de destaque no objeto-livro. Baseada nessa função, foram organizadas três categorias para identificar as instâncias de significação do livro: texto como 
instância primária, imagem como instância primária ou interação entre texto e imagem como instância primária.

Embora grande maioria dos livros possuisse ilustrações em sua composição para ajudar a compor a narrativa, 73\% desses livros têm o texto como primeira instância de significação. A percentagem de livros em que a interação entre texto e imagem é privilegiada, que ficou em $27 \%$, pode ser entendida como uma transição entre os livros em que a imagem é a maior responsável pela narrativa, usualmente definidos como livros para crianças, e que não tiveram representação nesse acervo, e os livros considerados adultos, em que o texto é a principal, senão a única linguagem. Todavia, esses números podem ser entendidos também como uma proposta de projeto para o objetolivro que une suas linguagens em prol da experiência literária do jovem estudante inscrito em uma sociedade visual. Contudo, deve-se observar que, dos 12 livros que possuem a interação entre texto e imagem como instância primária, 7 exemplares compreendem os livros de história em quadrinhos, que, pelas características próprias do gênero, veiculam sua narrativa por meio da interação entre texto e imagem.

\subsection{Tipologia a respeito da relação entre texto e imagem nos aspectos narrativos}

Para avaliarmos a relação que se estabelece entre texto e imagem nos seus aspectos narrativos e de construção de sentido, utilizamos novamente as considerações de Linden (2011) na organização de classificações.

- Relação de redundância: o sentido principal veiculado pelo texto e pela imagem apresenta redundância, ou seja, nenhuma das instâncias produz sentidos suplementares; ambas as instâncias remetem à mesma narrativa, tendo seus conteúdos total ou parcialmente sobrepostos.

- Relação de colaboração: texto e imagem se articulam para a construção de um discurso único, que não está presente unicamente em nenhuma das duas instâncias, mas que emerge da colaboração entre elas.

- Relação de disjunção: texto e imagem não necessariamente entram em contradição, mas não se identificam pontos de convergência entre as duas instâncias, como se texto e imagem seguissem por vias paralelas. Em obras com essa relação, o papel do leitor é de extrema importância para a construção do sentido da narrativa.

- Apesar dos critérios estabelecidos para a seleção dos livros pelo PNBE valorizarem um trabalho colaborativo entre texto e imagem (BRASIL, 2009), 59\% dos livros selecionados relaciona conteúdo textual e conteúdo imagético de forma redundante, sem acrescentar novas informações ou sentidos. A relação de 
colaboração, que atenderia a essa premissa, aparece em $39 \%$ do acervo, uma percentagem menor mas ainda representativa. Já a relação de disjunção, que pede um trabalho maior de interpretação e construção de sentidos por parte do leitor, tem uma participação de apenas $2 \%$, contando apenas com uma obra, que inclusive não aproveita o potencial de tal concepção em seu projeto, valendo-se de imagens padronizadas, que, embora divergindo do texto, não trazem novos significados para a leitura.

\subsection{Tipologia das diagramações para texto e imagem}

Foi analisada também a tipologia de diagramação das páginas, organizada nas seguintes categorias (Linden, 2011):

- dissociação: separa imagem e texto em páginas distintas;

- associação: rompe com a separação entre texto e imagem, reunindo ambos na mesma página, com estruturas que possibilitam diferentes graus associativos;

- compartimentação: organização das páginas em espaços divididos e emoldurados, que abrigam texto e imagem na construção da narrativa;

- conjunção: mescla diferentes linguagens e enunciados, articulando texto e imagem numa composição em que não é possível separá-los.

De acordo com essa classificação, observa-se que a diagramação mais utilizada, a associação, participa de $68 \%$ dos livros analisados, identificando a preferência por apresentar conteúdo textual e imagético em um espaço compartilhado. No entanto, a integração entre as duas linguagens, característica da conjunção, só alcançou $5 \%$ da amostra. A compartimentação também possui grande representatividade no universo estudado, aparecendo em $20 \%$ dos livros; mas é necessário lembrar que ela abrange todos os livros de história em quadrinhos. Fora desse gênero, apenas 2 livros apresentam a compartimentação como possibilidade de diagramação.

\subsection{Tipologia em relação à presença diferenciada dos elementos do design gráfico}

Procurando refinar os resultados alcançados até aqui, organizou-se a última categorização dessa pesquisa, abalizada nos novos fundamentos do Design, estabelecidos por Lupton \& Phillips (2008). Partindo dos fundamentos apresentados pelas autoras, organizou-se quatorze categorias: (1) ponto, linha, plano; (2) escala; (3) textura; (4) cor; (5) figura/fundo; (6) enquadramento; (7) hierarquia; (8) camadas; (9) transparência; (10) modularidade; (11) malha gráfica; (12) padronagem; (13) diagrama; (14) tempo e movimento. Para avaliar a 
presença dessas categorias nos livros analisados, foram utilizados os mesmos critérios apresentados anteriormente para classificação da tipologia em relação ao diferencial gráfico.

Baseado nessa classificação, percebe-se que apenas 10 livros dos 50 livros analisados não apresentam em seu projeto nenhum fundamento do Design que se destaque; número bem inferior aos 30 livros que não apresentaram nenhum diferencial gráfico na tipologia realizada anteriormente. Mas é importante frisar que muitas vezes os elementos que caracterizam o uso de um conceito não aparecem no design em si, mas como parte do projeto de ilustração; como também, apesar de o conceito estar presente na composição do design do livro, muitas vezes sua presença não agrega valor ao processo de significação realizado pelo leitor durante a experiência literária. O conceito de escala, utilizado majoritariamente na composição de capitulares, foi o mais encontrado no acervo estudado, estando presente em 16 livros. O conceito de cor, que também teve uma participação significativa, presente em 15 livros, repete os dados encontrados na análise do diferencial gráfico.

\section{ANÁLISE QUANTITATIVA: um panorama dos aspectos gráficos presentes nos livros para jovens estudantes}

A partir dos resultados encontrados na etapa de categorização e análise quantitativa, foi possível formar um panorama dos aspectos gráficos presentes nos livros para jovens estudantes e dos lugares ocupados pelo Design neste cenário.

- A grande presença de imagens na composição dos livros selecionados para o jovem constituiu uma surpresa durante a pesquisa, principalmente pelo fato de, em $73 \%$ dos livros que possuem ilustração, o texto exercer a função de instância primária, e, em 59\%, as imagens estabelecerem uma relação de redundância com o texto, não acrescentando novos sentidos à experiência de leitura. De acordo com os Parâmetros Curriculares Nacionais (Brasil, 1998), o trabalho com a linguagem a ser desenvolvido com o jovem inclui a ampliação de formas de raciocínio e abstração, e, no edital de seleção do PNBE (Brasil, 2009), o trabalho colaborativo entre o conteúdo textual e imagético é valorizado. Dessa forma, acredita-se que objetos-livro que possuam função de colaboração ou de disjunção entre conteúdo textual e imagético estariam mais próximos do jovem estudante e deveriam, portanto, fazer-se mais presentes na composição dos acervos do PNBE.

- Apesar da grande presença de imagens, os elementos de design relacionados à própria constituição do objeto-livro são tratados, na grande maioria das vezes, de forma padrão, sem apresentar características de um trabalho diferenciado; e os fundamentos 
do Design não são utilizados na composição do livro ou aparecem de forma isolada e desconectada do conteúdo textual e imagético, o que distancia esses livros do conceito de Design na Leitura.

- Apenas 12 livros tiveram sua instância primária identificada como a interação entre conteúdo textual e conteúdo imagético. Se descartarmos desse número os 7 livros de história em quadrinhos, devido às características inerentes ao próprio gênero a que pertencem, apenas 5 obras, ou seja $10 \%$ do acervo total, possuem um projeto de diálogo entre as linguagens que constituem o objeto-livro.

- 59\% dos livros que possuem ilustrações apresentam conteúdos redundantes nas duas linguagens. Por meio desses dados, não apenas podemos afirmar que grande parte dos livros selecionados se afastam da experiência literária pensada para o jovem estudante, como mencionado anteriormente, assim como não atendem ao conceito de Design na Leitura.

\section{ANÁLISE COMPARATIVA: o design como mediador de leitura}

Resumindo os dados apresentados, podemos afirmar que apesar da identificação de algumas obras possuidoras de projetos que valorizam a fruição do leitor e o diálogo entre as linguagens que os compõem, a grande maioria dos livros do acervo do PNBE 2011 para os anos finais do Ensino Fundamental não reconhece o lugar social do jovem leitor e desconsidera o conceito de Design na Leitura. Por meio dos dados coletados, percebe-se que o Design tem sido considerado, na maioria das vezes, mero agente produtor na cadeia editorial, e não um campo de saber presente no próprio desenvolvimento do objeto-livro, capaz de colocar em diálogos as diversas linguagens que o compõem. As possibilidades instauradas pelo Design enquanto atividade projetual interdisciplinar não estão sendo exploradas na constituição desses objetos.

Como forma de melhor exemplificar o conceito de Design na Leitura e os dados recolhidos na pesquisa apresentada, expomos a seguir a análise gráfica de dois livros pertencentes ao acervo estudado. Ao compararmos os projetos gráficos desenvolvidos para os livros $O$ mistério do fundo do pote, de Ilo Krugli (2007), e A bruxinha que era boa e outras peças, de Maria Clara Machado (2009), ambos textos teatrais, podemos identificar a mediação de leitura realizada pelo Design. 
Figura 1 Capa e páginas 10-11, 14-15, 32-33, 84-85 e 86-87 do livro $O$ mistério do fundo do pote, com texto de Ilo Krugli e ilustrações de Gonçalo Cárcamo, editado pela Comboio de Corda - SM apresentando, respectivamente, a listagem de personagens, o início da peça e parte do póstextual intitulado "Pensando a Cena".

Fonte: KRUGLI, 2007.

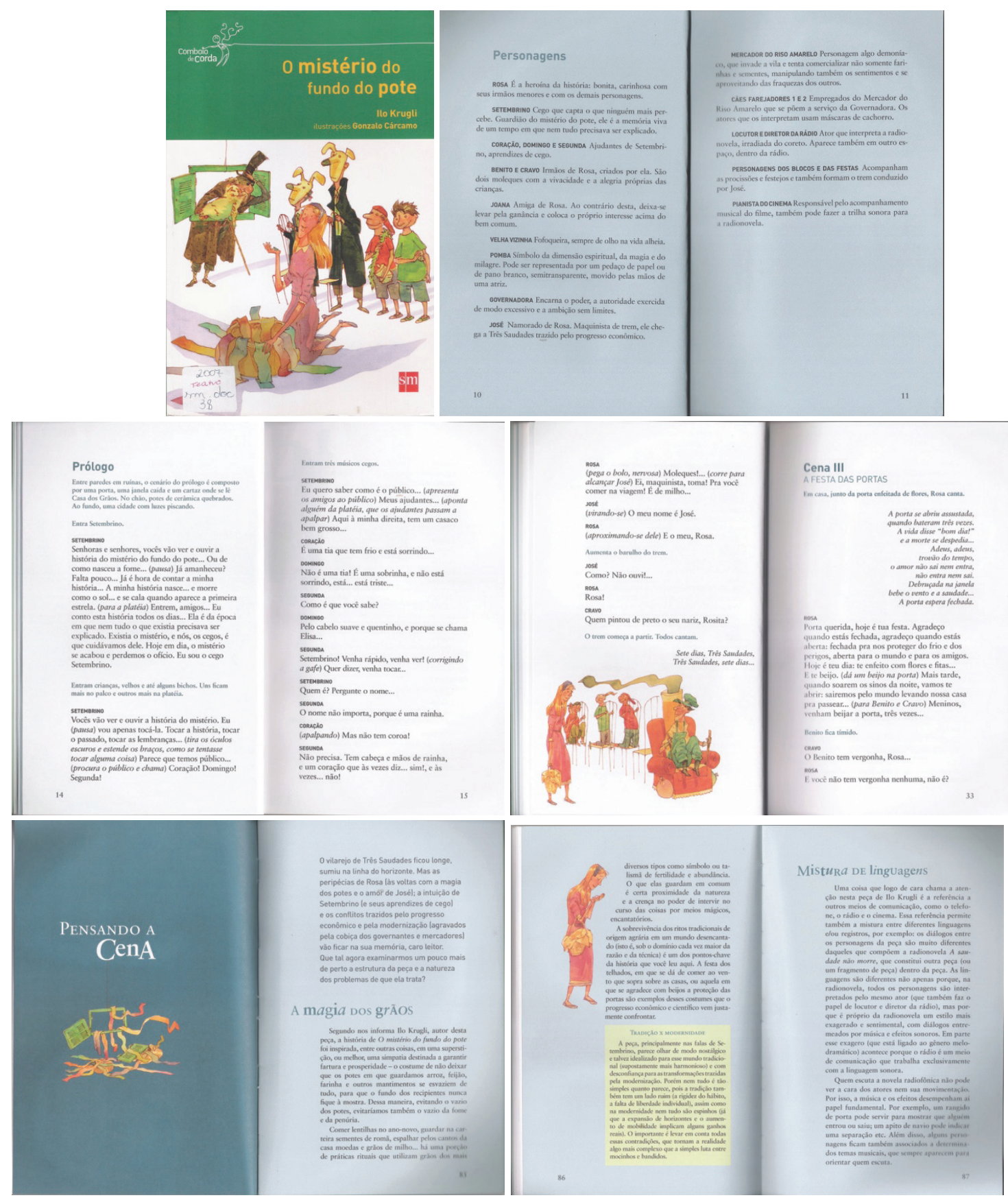

O livro de Ilo Krugli, com ilustrações de Gonçalo Cárcamo e com projeto gráfico sem autor identificado, publicado pela editora Comboio de Corda - SM, se utiliza de elementos gráficos para 
apresentar em papel impresso o texto feito para ser ouvido e visto em palcos. Tendo aproximadamente $35 \%$ de suas páginas com a presença de imagens, as ilustrações de $O$ mistério do fundo do pote ajudam a caracterizar a história da trama teatral, os personagens e suas ações. Para a organização do conteúdo textual, que, pela especificidade do gênero, apresenta diversos tipos de informações, como falas, descrição de cenário, descrição de ações etc., o projeto gráfico desenvolvido se utiliza de um trabalho tipográfico e cromático diferenciado, utilizando os fundamentos de cor e hierarquia para mediar a experiência de leitura.

Como pode-se observar nas imagens, tipografia e cor trabalham de forma conjunta para permitir que o leitor identifique as diferenças e as hierarquias entre cada conteúdo apresentado. A utilização de fontes diferentes para o nome do personagem (fonte sem serifa e bold), para a sua fala (fonte serifada com peso normal) e para a descrição das ações (fonte serifada em itálico) proporciona conforto e fácil compreensão ao ato de leitura. Já a utilização do azul como cor auxiliar para o texto, separando as descrições do cenário e do contexto da cena das falas dos personagens, permite organizar e harmonizar os conteúdos, além de proporcionar ritmo para a leitura.

Outro exemplo do trabalho diferenciado na tipografia e nas cores é encontrado na parte final do livro, que se propõe a examinar "(...) um pouco mais de perto a estrutura da peça e a natureza dos problemas de que ela trata (...)" (Krugli, 2007, p. 14). Em Pensando a Cena, a tipografia dos subtítulos apresenta um trabalho diferenciado, formando as palavras a partir de letras de diferentes famílias tipográficas. Já a cor no fundo da página, da mesma forma que ocorre nas páginas de apresentação dos personagens e dos cenários no início do livro, estabelece uma diferenciação das páginas brancas que contam a história. Outra utilização da cor, com a função de separar e identificar diferentes textos, é o uso do quadro amarelo, que permite trazer observações e destacar sugestões para a implementação da peça teatral.

O texto, principal veiculador da narrativa apresentada, tem a função de instância primária do livro. As imagens funcionam em uma relação de redundância com o texto, permitindo a visualização de soluções possíveis para a montagem teatral da história apresentada, mas não adicionando novos elementos à narrativa. Já a tipologia de diagramação utilizada é, primordialmente, a associação, com as imagens dividindo o espaço da página com o texto.

Com tema que trata, por meio da fantasia, da constituição de valores, da organização social e do desenvolvimento tecnológico, $O$ mistério do fundo do pote se encontra bem direcionado para o público juvenil e utiliza o design para melhor apresentar os diferentes conteúdos que compõem o gênero teatral, em um projeto voltado para a experiência de leitura que será gerada pelo objeto-livro. Dessa forma, podemos afirmar que o livro se aproxima dos conceitos de Design na Leitura. Todavia, ao analisarmos o livro A bruxinha que era boa e outras 
peças, de Maria Clara Machado, editado pela Ediouro Publicações de Passatempos e Multimídia, com projeto gráfico sem autor identificado, podemos verificar situação oposta.

Figura 2 Capa e páginas 6-7, 8-9 e 10-11 do livro A bruxinha que era boa e outras peças, de Maria Clara Machado, editado pela Ediouro Publicações de Passatempos e Multimídia, apresentando, respectivamente, a abertura da peça, os personagens e o cenário juntamente com o início da peça. Fonte: MACHADO, 2009.

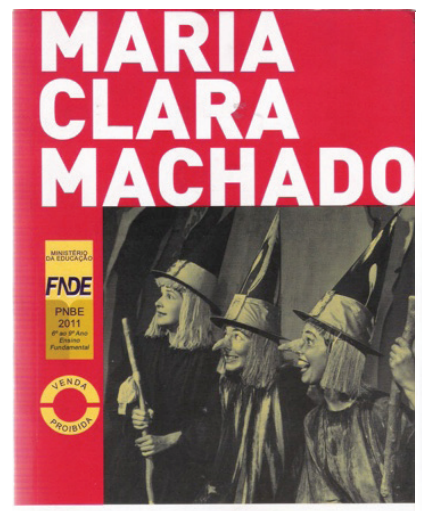

A BRUXINHA QUE ERA BOA e outras peças
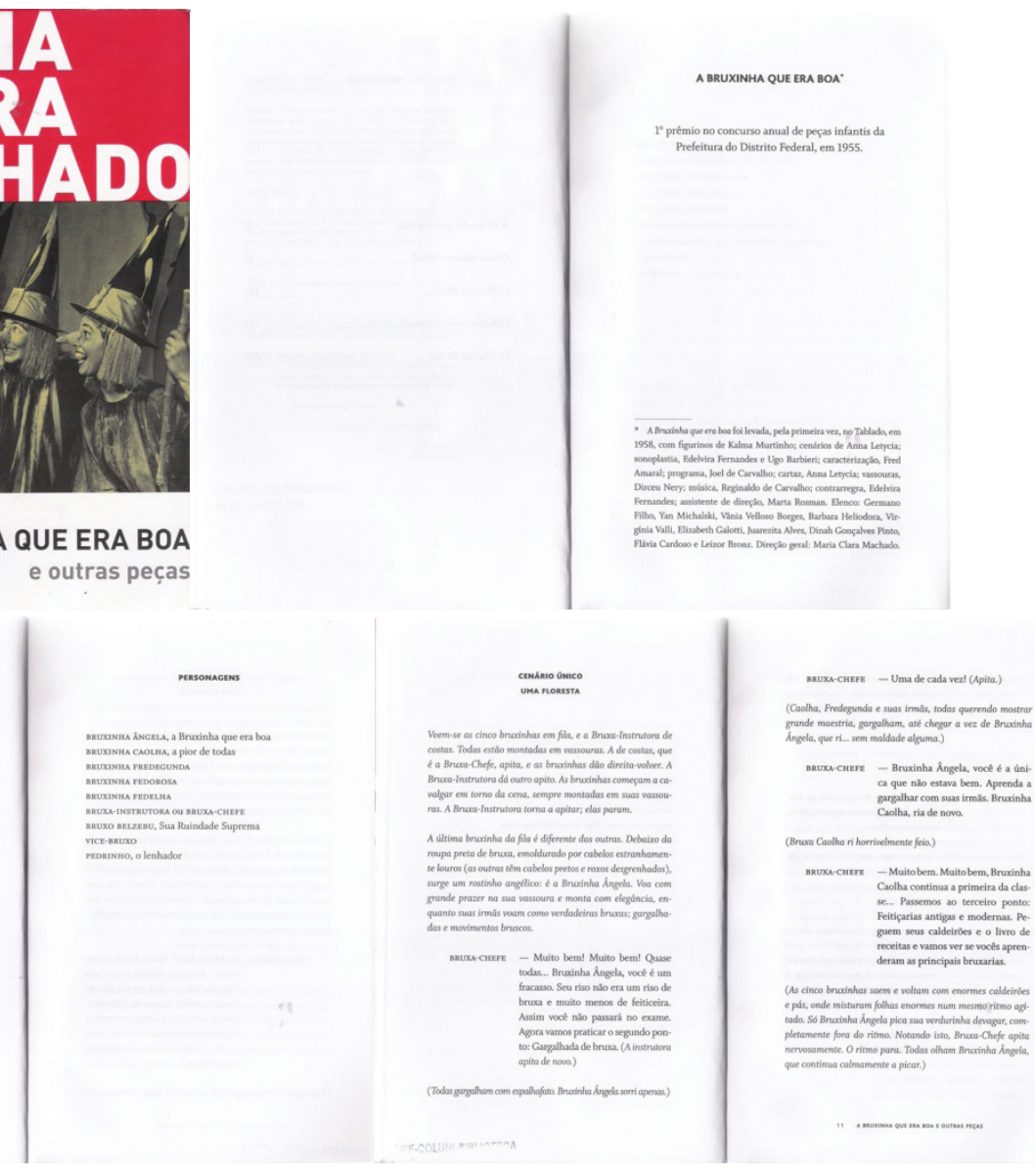

A análise apresentada possibilita a demonstração não apenas do papel de mediador de leitura exercido pelo Design, mas evidencia a formação díspar do acervo formado pelo PNBE em relação aos atributos gráficos dos livros selecionados. Enquanto em $O$ mistério do fundo do pote, o projeto gráfico conta com ilustrações e trabalho diferenciado no uso da tipografia e das cores para estabelecer a hierarquia textual, possibilitando que o leitor contextualize as diferentes marcações e as relacione, em A bruxinha que era boa e outras peças, essas marcações são apresentadas de maneira uniforme com diferenças apenas no peso da fonte e o espaço de indentação do texto, conforme a escrita tradicional de roteiros de teatro, resultando em mancha textual sem destaque para seus elementos. Apesar da 
qualidade do texto de Maria Clara Machado e de sua adequação ao público de jovens estudantes, a apresentação gráfica dada à obra, que não se utiliza de qualquer imagem, a afasta do conceito de Design na Leitura, por não constituir um projeto voltado para a fruição do jovem leitor, dificultando o movimento de aproximação do jovem da leitura.

\section{CONCLUSÃO: formulando propostas}

A partir da análise apresentada, percebemos o papel exercido pelo Design na construção de significado, e identificamos que a experiência do leitor é valorizada quando o objeto-livro é composto mediante uma atividade projetual capaz de abraçar as diversas linguagens constituintes do objeto-livro e integrar texto, ilustração e design gráfico, pondo em diálogo conteúdo verbal e conteúdo icônico. Considerando que o contato com livros possuidores de um projeto de Design na Leitura, além de possibilitar a aproximação do jovem da leitura literária, permite a construção de um olhar consistente sobre a imagem e participa da constituição da cultura visual do jovem, é importante ressaltar a influência do Design na formação do sujeito e na posição que ele ocupará na sociedade. Para que se alcance esse potencial dialógico, contudo, é fundamental reconhecer o Design como mediador de leitura, capaz de articular as diversas linguagens constituintes do objeto-livro e atuar na experiência literária por ele gerada.

Com a formalização do conceito de Design na Leitura e a compreensão da articulação possível entre a fruição do texto e o lugar social do leitor, esperamos contribuir para modificar o paradigma instaurado no mercado editorial contemporâneo, aparente nos resultados da análise realizada, e por isso gostaríamos de recomendar a incorporação do conceito de Design na Leitura aos critérios de avaliação de livros para o PNBE. Por meio de uma seleção que compreenda o Design como atividade interdisciplinar e mediadora de leitura, considerando em seu projeto a fruição do jovem leitor, acreditamos que seja possível alcançar um acervo que aproxime o jovem da experiência literária. Assim, de forma mais efetiva, pode-se também ultrapassar a experiência de fruição pessoal, atingindo a formação de uma sociedade leitora hábil na compreensão do texto e da imagem.

Em apoio às considerações acima, visando a melhor constituição do acervo, acreditamos que, juntamente com a efetivação do Design na Leitura como conceito participante da avaliação dos livros, é necessária a constituição de um conjunto de iniciativas com vistas a incorporar um projeto de formação continuada do magistério, de forma a propiciar a percepção das contribuições do projeto gráfico para o ato de leitura. Dessa forma, propõe-se a confecção de um guia que apresente os livros pertencentes aos acervos do PNBE, com 
resenhas que contemplem não apenas o conteúdo textual, mas que discorram sobre as demais linguagens formadoras dos objetos-livro e sobre as relações estabelecidas entre elas, com foco no Design na Leitura. Esse guia teria formato similar àqueles já formulados para acompanhar os livros comprados por outros programas do governo, como os guias formulados para orientar os professores na escolha dos livros didáticos das diversas disciplinas, parte integrante do Programa Nacional do Livro Didático - PNLD, que apresenta os critérios de avaliação das coleções e resenhas das obras aprovadas pelo governo. Acredita-se que o desenvolvimento desse guia, que não deve se caracterizar como um manual de instruções, poderia possibilitar que os educadores conheçam os acervos formados pelo PNBE e os critérios utilizados na sua seleção. No entanto, para que se estabeleça um verdadeiro contato entre os mediadores e os livros que serão oferecidos aos jovens estudantes, propõe-se ainda a organização de um curso de formação continuada para os professores, bibliotecários e demais mediadores de leitura pertencentes à rede pública de ensino. Nesse curso, que poderia funcionar no formato de oficinas, os mediadores teriam a oportunidade de assumir o lugar dos leitores, trocando impressões e experiências com seus colegas de profissão, sendo orientados por um profissional que apresentasse o conceito de Design na Leitura como uma possibilidade de mediação.

Ao organizar essas propostas, esperamos, mesmo que de forma ainda inicial, possibilitar a instauração de uma política de Design na Leitura presente nas políticas públicas de formação de leitores, de forma a considerar o livro como objeto concebido para a fruição do leitor e voltado para a formação de uma sociedade leitora.

\section{REFERÊNCIAS}

BRASIL. Secretaria de Educação Fundamental. Parâmetros curriculares nacionais: terceiro e quarto ciclos do ensino fundamental: língua portuguesa. Brasília: MEC/ SEF, 1998. . Ministério da Educação. Edital de convocação para inscrição de obras de literatura no processo de avaliação e seleção para o Programa Nacional Biblioteca da Escola - PNBE 2011. Brasília, 2009.

HASLAM, Andrew. O livro e o designer II: como criar e produzir livros. Tradução Juliana A. Saad e Sérgio Rossi Filho. São Paulo: Edições Rosari, 2007.

KRUGLI, Ilo. O mistério do fundo do pote. Ilustrações Gonzalo Cárcamo. São Paulo: Comboio de Corda, 2007.

LINDEN, Sophie Van der. Para ler o livro ilustrado. Tradução Dorothée de Bruchard. São Paulo: Cosac Naify, 2011.

LUPTON, Ellen; PHILLIPS, Jennifer Cole. Novos fundamentos do design. Tradução Cristian Borges. São Paulo: Cosac Naify, 2008.

MACHADO, Maria Clara. A bruxinha que era boa e outras peças. Rio de Janeiro: Ediouro Publicações de Passatempos e Multimídia, 2009. 
QUEIRÓS, Bartolomeu Campos de. Manifesto. [2009] In: MOVIMENTO POR UM BRASIL LITERÁRIO. O Manifesto. Disponível na internet por http em: http://www2.brasilliterario.org.br/pt/manifesto/o-manifesto Acesso em 17 mar. 2016.

\section{Sobre os autores}

\section{Maíra Gonçalves Lacerda}

maira_lacerda@hotmail.com

PUC-Rio - Pontifícia Universidade Católica do Rio de Janeiro

Departamento de Artes e Design

Programa de Pós-graduação em Design

LINC-Design - Laboratório Linguagem, Interação e Construção de Sentidos

\section{Jackeline Lima Farbiarz}

jackeline@puc-rio.br

PUC-Rio - Pontifícia Universidade Católica do Rio de Janeiro

Departamento de Artes e Design

Programa de Pós-graduação em Design

LINC-Design - Laboratório Linguagem, Interação e Construção de Sentidos

Edição especial P\&D2016

Artigo recebido em 23/09/2016

Artigo aceito em 30/09/2016 